\title{
Discouraging Conclusions on Initial Opioid Prescriptions
}

\section{TO THE EDITOR:}

In a manuscript published in the New England Journal of Medicine, Zhu et al (1) have provided information on initial opioid prescriptions among U.S. insured patients with a decline of $54 \%$ to $68 \%$, accompanied by a decrease in providers. However, authors have inappropriately concluded that a subgroup of providers continue to write high risk initial opioid prescriptions. Multiple factors may be at play for these prescriptions. Further, the journal also published multiple manuscripts in reference to adverse effects of curtailing opioid prescriptions: as structural iatrogenesis (2) and ill effects of opioid use disorder and incarceration (3). The CDC report (4) through 2017 shows no change in death rate related to prescription opioids, whereas, there was astronomical increase related to deaths related to synthetic opioids (Fig. 1). Therefore, a significant contribution to the current opioid epidemic includes fentanyl and heroin (5). Reframing prevention strategies must be linked to true causes. Thus, while we should not take our eye off of prescription opioid issues, at the same time, we should not exaggerate the newly developing issue of curbing opioids for medically necessary patients

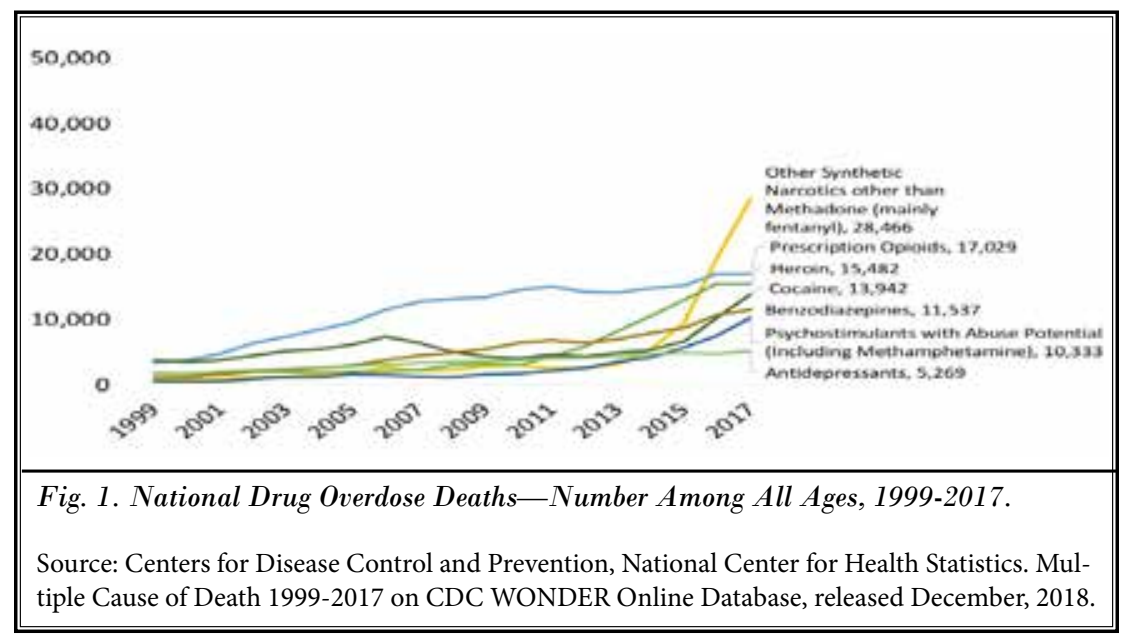

which in turn may be contributing to heroin and fentanyl epidemic.

Laxmaiah Manchikanti, MD

Clinical Professor

Anesthesiology and

Perioperative Medicine

University of Louisville, Kentucky

Professor

of Anesthesiology-Research

Department of Anesthesiology,

School of Medicine

LSU Health Sciences Center

Co-Director

Pain Management Centers of America

67 Lakeview Drive

Paducah, KY 42001

E-mail: drlm@thepainmd.com

Alan D. Kaye, MD, PhD

Professor, Program Director, and Chairman
Department of Anesthesiology Louisiana State University

Health Science Center

1542 Tulane Ave, Room 659

New Orleans, LA 70112

E-mail: akaye@lsuhsc.edu

Joshua A. Hirsch, MD

Vice Chair and

Service Line Chief

Interventional Radiology

Chief of Neurolnterventional Spine

Director

Interventional Neuroradiology

Massachusetts General Hospital

Associate Professor of Radiology

Harvard Medical School

55 Blossom St., Gray 241B

Boston, MA 02114

E-mail:

jahirsch@mgh.harvard.edu 


\section{References}

1. Zhu W, Chernew ME, Sherry TB, Maestas N. Initial opioid prescriptions among U.S. commercially insured patients, 20122017. N Engl J Med 2019;380:1043-52.

2. Stonington S, Coffa D. Structural iatrogenesis - A 43-year-old man with "opioid misuse". N Engl] Med 2019;380:701-4.
3. Binswanger IA. Opioid use disorder and incarceration - hope for ensuring the continuity of treatment. $N$ Engl J Med 2019; 380:1193-95.

4. Scholl L, Seth P, Kariisa M, Wilson N, Baldwin G. Drug and opioid-involved overdose deaths - United States, 20132017. MMWR Morb Mortal Wkly Rep
2018;67:1419-27.

Manchikanti L, Sanapati J, Benyamin RM, Atluri S, Kaye AD, Hirsch JA. Reframing the prevention strategies of the opioid crisis: Focusing on prescription opioids, fentanyl, and heroin epidemic. Pain Physician 2018;21:309-26. 